\title{
O debate sobre a reforma agrária no contexto do Brasil rural atual
}

Lauro Mattei'

\section{Resumo}

Neste artigo, faz-se uma breve discussão sobre as principais teses em debate sobre a pertinência da reforma agrária no início do século XXI. Parte-se de uma contextualização do meio rural brasileiro atual após décadas de transformações estruturais para, posteriormente, apresentar as teses favoráveis e as teses contrárias à reforma agrária. Por um lado, observa-se que existe um grupo expressivo de pesquisadores que defende a reforma agrária por entender que este ainda é um instrumento eficaz no combate à pobreza e as desigualdades sociais e regionais e, por outro, registra-se a presença de um grupo de pesquisadores que avaliam que o tempo da reforma agrária já passou e que este não é mais um instrumento necessário no Brasil no século XXI. Concluímos que, neste cenário, o debate acadêmico é bem menos relevante comparativamente aos períodos anteriores, especialmente durante o pós-guerra.

Palavras-chave: Brasil. Desenvolvimento rural. Reforma agrária.

\section{Introdução}

As últimas décadas do século XX foram marcadas por importantes mudanças na estrutura produtiva e na dinâmica socioeconômica rural brasileira, com impactos sobre as distintas formas de agricultura e de ocupaçóes existentes em todas as grandes regióes do país. Diversos fatores contribuíram decisivamente para conformar esse novo cenário, destacando-se a consolidação de um modo de produçáo capitalista na agricultura assentado na produçáo de commodities agropecuárias em larga escala; o intenso processo migratório no sentido rural-urbano; as mudanças expressivas nos processos de trabalho por meio da adoção de princípios e técnicas ligadas ao padrão global de acumulação de capital; a emergência e expansão de novas formas de ocupação das populações rurais; novas formas de reordenação dos espaços geográficos rurais relacionados às esferas da produção e do consumo; e o surgimento de

Professor do curso de Graduação em Economia e do Programa de Pós-Graduação em Administração, ambos da Universidade Federal de Florianópolis (UFSC). Coordenador geral do NECAT-UFSC e Pesquisador do OPPA/ CPDA/UFRRJ.E-mail: I.mattei@ufsc.br 
novos temas relacionados ao mercado de trabalho rural, como são os casos das duplas ocupaçóes, da pluriatividade e da multifuncionalidade da agricultura.

A partir dessas transformaçóes estruturais gerou-se uma nova dinâmica nas relaçóes econômicas e sociais no meio rural brasileiro, as quais alteraram a estrutura e a composição do trabalho rural. Por um lado, a expansão desse novo padrão produtivo conduziu a um processo crescente de integração da agricultura aos demais setores econômicos, fazendo com que o ritmo e a dinâmica da produçáo estejam cada vez mais subordinados aos movimentos gerais da economia do país. Por outro, a integração vertical da produção naquilo que ficou conhecido com os complexos agroindustriais alterou o mercado de trabalho agrícola e o poder de decisáo sobre o processo produtivo. Agora, a decisão sobre o que produzir e como produzir deixou de ser uma tarefa específica do agricultor e passou a ser condicionada por uma série de variáveis determinadas pelo conjunto de agentes econômicos envolvidos no processo produtivo. Isso significa dizer que atualmente o poder decisório está muito mais concentrado no âmbito de determinados segmentos da cadeia produtiva e bem menos na figura do agricultor.

De um modo geral, verifica-se que essas mudanças impactam mais fortemente o sistema da agricultura familiar, o qual vem se especializando e permitindo que as lides agrícolas sejam crescentemente asseguradas apenas pelo chefe da exploração, liberando os demais membros familiares que passam a buscar ocupação em atividades fora da agricultura. Nessa lógica, é crescente o número de famílias de agricultores das regióes com grande presença do sistema familiar de produção agrícola que procuram se reproduzir socialmente desenvolvendo, simultaneamente, atividades agrícolas e não agrícolas, com implicaçóes diretas sobre a dinâmica geral do emprego no meio rural do país.

Especificamente em relação ao trabalho rural, é perfeitamente visível a subordinação dos agricultores à dinâmica global do capital, uma vez que as agroindústrias passam a deter um maior controle sobre as açóes dos agricultores, abrindo a perspectivas para que estes se transformem em empregados a domicílio, porém sem qualquer vínculo empregatício formal. Além disso, outras transformaçóes em curso promovem também uma expansão da flexibilização e da informalização do trabalho agrícola, fato que pode ser observado no aumento do número de agricultores com emprego fora das propriedades, bem como na combinação de diferentes atividades dentro da própria 
propriedade, atividades estas que nem sempre estáo diretamente relacionadas à produção agrícola.

Nesse processo de mudanças, ocorreu também um agravamento da questão agrária, uma vez que, além das açôes governamentais nessa esfera serem bastante tímidas e limitadas, o nível de concentração fundiária aumentou fortemente. Por exemplo, tomando-se o Índice de $\mathrm{Gini}^{2}$ como referência, nota-se que o Brasil figura entre os países com as maiores taxas de concentração de terra do mundo.

Para Delgado (2014), a questão agrária e a reforma agrária são conceitos interdependentes, mas autônomos, porém ambos se reportando à estrutura agrária do país e seguindo itinerários históricos próprios. O primeiro trata da estrutura, posse e uso da terra no país, enquanto que o segundo contém a proposição política de reforma dessa mesma estrutura, ou seja, um conjunto de políticas públicas que fosse capaz de modificar determinada estrutura agrária que historicamente foi se consolidando no país.

Já Graziano da Silva (1985a) diferencia a questáo agrícola da questão agrária para ressaltar a importância da política de reforma agrária. Assim, enquanto a primeira diz respeito aos aspectos ligados às mudanças na produção em si mesma (o que, onde e quanto se produz), a segunda está ligada às transformaçôes nas relaçôes de produção e de trabalho e no acesso à terra. Por isso, os indicadores da questão agrária vão bastante além da simples medição de quantidades produzidas e de preços recebidos.

Para Delgado (2014), a modernização conservadora da agricultura implementada a partir da década de 1960, enquanto estratégia de Estado, e explicitou a negaçáo de qualquer mudança da estrutura agrária do país, ao não se implantar políticas efetivas de reforma agrária. Com o fim do regime militar e a volta da normalidade democrática, o tema da reforma agrária foi reposto na agenda política nacional, mesmo que de maneira distinta daquela dos anos de 1960.

Com isso, nas três últimas décadas, o debate sobre a reforma agrária ganhou nova dimensão, inclusive fazendo parte de forma destacada da agenda

2 Este índice varia de 0 a I, sendo que quanto mais próximo de I maior é o grau de concentração. No caso da terra, o último Censo Agropecuário (2006) revelou que o Índice de Gini da concentração de terra no Brasil é de 0,854 . 
dos governos e dos diversos atores sociais rurais. Particularmente em todos os debates acadêmicos recentes sobre o modelo de desenvolvimento brasileiro, a reforma agrária voltou a ter um papel de destaque, mesmo que de forma náo consensual. De um modo geral, pode-se dizer que essas discussóes procuram fazer uma conexão entre a atual estrutura agrária do país e os temas da pobreza rural, da dinâmica populacional, do desemprego, da modernizaçáo da agricultura, das mudanças nas relaçóes de trabalho no campo e do êxodo rural.

Diante do questionamento sobre a pertinência de um programa de reforma agrária para a sociedade brasileira contemporânea, as respostas são bem distintas no âmbito acadêmico, onde residem, sem dúvida, as maiores contradiçóes desse debate. Por um lado, diversos pesquisadores das áreas das Ciências Sociais, Humanas e Agrárias vêm afirmando que o desenvolvimento agrário brasileiro das últimas cinco décadas rebaixou o problema fundiário, fazendo com que o tema da reforma agrária deixasse de ser uma reivindicação nacional e um instrumento decisivo capaz de alterar os destinos históricos do desenvolvimento do país. Para esses autores, a reforma agrária perdeu sua centralidade no debate nacional. Por outro lado, grupos de pesquisadores das mesmas áreas de conhecimento citadas procuram mostrar a relevância e a atualidade da reforma agrária para o Brasil, especialmente em função dos elevados índices de concentraçáo de terra e dos graves problemas econômicos e sociais existentes no meio rural, motivos estes que estimulam a ocorrência de graves conflitos agrários em várias regiōes do país.

Neste sentido, o objetivo deste artigo é sistematizar os principais argumentos de cada um desses posicionamentos em relação à realização da reforma agrária. Para tanto, além desta breve introdução, o texto contém mais três seções. A primeira delas faz uma breve discussão sobre o contexto rural do país, destacando as dinâmicas regionais das diversas estruturas produtivas. A segunda seção sistematiza os principais argumentos favoráveis e contrários à reforma agrária. A terceira seção apresenta as consideraçóes finais do trabalho, realçando o cenário e as perspectivas da reforma agrária no Brasil.

\section{Breve contexto rural brasileiro}

As últimas décadas do século XX apresentaram grandes mudanças nos sistemas produtivos agroalimentares mundiais, com impactos diretos em todos os países e regióes. A partir do pós-guerra, o mundo conviveu com um 
processo crescente de homogeneização desses sistemas, cuja matriz foi o modelo produtivo que se assentou nos princípios da revolução verde, destacando-se aí o uso de sementes melhoradas, dos adubos químicos, dos agrotóxicos e da maquinaria agrícola. Dessas mudanças nos padróes produtivos emergiram também novas formas de regulação das economias capitalistas com impactos diretos sobre o mundo do trabalho, tanto rural como urbano. No caso dos sistemas agroalimentares ocorreram impactos específicos, uma vez que a formação desse sistema mundial aumentou o nível de integração vertical da agricultura no âmbito da economia. Não há dúvidas de que essa passagem foi fortemente marcada pela presença ativa das políticas agrícolas implementadas pelos países desenvolvidos, em especial pelos EUA e pela Comunidade Europeia, políticas estas que tinham uma dimensão extremamente protecionista para os produtores internos e seus respectivos produtos. Desse modo, configura-se também todo um aparato institucional que, se por um lado levou esses países a autossuficiência produtiva, por outro lado causou distorçóes significativas que impactaram fortemente a dinâmica da produção agrícola nos países da periferia do sistema capitalista.

No Brasil, o conjunto dessas transformaçóes estruturais, conhecido genericamente como "modernização da agricultura", já foi amplamente estudado e documentado, merecendo destaque apenas os principais aspectos e consequências desse processo. Com a expansão da produção econômica-industrial, assentada nos pressupostos do "modelo de substituição de importaçóes", a agricultura deixou de ser um setor econômico distinto e rapidamente passou a ser integrada à dinâmica da produção industrial, naquilo que ficou conhecido como "Complexos Agroindustriais", conectando a agricultura com os outros ramos de produçáo industrial. Com isso, para produzir ela depende cada vez mais dos insumos que recebe de determinados setores industriais, náo produzindo apenas bens de consumo final, mas também bens intermediários ou matérias-primas para outros segmentos da indústria de transformação.

Em linhas gerais, é possível destacar alguns elementos centrais dessas mudanças estruturais que ocorreram nas últimas décadas. Nas áreas de fronteira agrícola, notadamente nas regióes Centro-Oeste e Norte do país, as lavouras tradicionais foram sendo substituídas por produtos agrícolas comerciais, conjuntamente com a expansão da produção animal de forma extensiva. Gasques e Villa Verde (1990) mostraram que, nestas regióes de fronteira agrícola, 
alterou-se o perfil tradicional da ocupação agrícola que vigorou até a década de 1980 diante do novo cenário assentado em uma agricultura fortemente mecanizada. Decorrem daí dois fatores essenciais: por um lado, a elevação da produtividade do trabalho agrícola, comparativamente às demais regióes do país e, por outro, pequenas reduçóes dos índices de pessoal ocupado na agricultura.

Paralelamente a esse fator mais regionalizado, observa-se que, em todo o país, ocorreu uma substituição crescente das lavouras tradicionais com uso intensivo de trabalho por culturas agrícolas modernas e com baixo uso de mão de obra, além da expressiva incorporação das inovaçóes tecnológicas em praticamente todas as etapas do processo produtivo, sobretudo naquelas culturas que ocupavam enormes quantidades de trabalhadores, como são os casos da cana-de-açúcar, do algodão, do café etc.

Quanto aos efeitos do fator "substituição de lavouras", observa-se que esse processo também não apresenta uma uniformidade regional. $\mathrm{Na}$ regiáo Norte do país, por exemplo, a expansão da produção ocorreu através das lavouras comerciais, principalmente do milho e soja, em detrimento das lavouras de subsistência (arroz, feijão, mandioca etc.). Já na regiáo Centro-Oeste, a substituição ocorreu fundamentalmente nas áreas dos produtos alimentares (arroz, feijão) e de pecuária extensiva com a introdução das culturas comerciais, destacando-se a soja e o milho. Isso representa uma importante alteração na característica tradicional de expansão e ocupaçáo das fronteiras agrícolas do país. Finalmente, na regiáo Nordeste assistiu-se, nas últimas décadas, a uma perda de centralidade de culturas agrícolas que tradicionalmente ocupavam muita mão de obra, em particular a cana-de-açúcar, o algodáo e o cacau, paralelamente à emergência e consolidaçáo de polos frutíferos regionais, porém com baixos índices de ocupação de trabalhadores, dado o elevado nível tecnológico incorporado ao processo produtivo.

A regiâo Sul apresenta uma base produtiva agrícola altamente diversifica$\mathrm{da}$, a qual se expressa nos diferentes sistemas de produção que foram adotados, tanto pelos agricultores familiares como por parte dos agricultores patronais. Especificamente em relaçáo à agricultura familiar da regiáo, nota-se que a trajetória histórica dessa forma de produção acabou gerando uma diferenciação social em seu meio, uma vez que encontramos de agricultores capitalizados a agriculturas em transiçáo e aqueles segmentos totalmente descapitalizados e 
sem condiçóes de acompanhar o ritmo das mudanças produtivas que foram implementadas na região. Por ser uma regiáo com grande concentração de agricultores familiares, o Sul do país apresenta uma enorme diversidade que pode ser sintetizada em quatro grandes grupos: a produçáo exclusiva para autoconsumo; a produçáa para autoconsumo e para o mercado; a produçáo integrada às grandes agroindústrias; e a produçáo de commodities para os mercados nacional e internacional.

Por fim, a regiáo Sudeste, por ser o espaço geográfico com o maior grau de industrialização do país, apresenta uma tendência forte de redução do emprego agrícola. Por um lado, culturas que tradicionalmente empregavam muitos trabalhadores agrícolas, particularmente a cana-de-açúcar, a laranja e o café, reduziram suas demandas devido ao processo contínuo de mecanizaçáo de praticamente todas as etapas de produção, e por outro, a agricultura com base no sistema familiar é cada vez menos expressiva em praticamente todas as unidades da federação dessa regiáo. Deve-se registrar, todavia, que todo esse processo de mudanças foi fortemente condicionado pelas políticas públicas implementadas pelo Estado, sendo inegáveis os efeitos das mesmas sobre a base produtiva rural. Por um lado, verificaram-se expressivos aumentos da produtividade das principais culturas e, por consequência, da produção agropecuária total do país, transformando o Brasil em um dos grandes exportadores do mundo. Mas, por outro lado, gerou-se uma série de consequências negativas, particularmente na esfera social, com destaque para a forte diferenciaçáo social entre os agricultores, a precarizaçáo das condiçóes de trabalho no meio rural, a elevação dos índices de pobreza, e a contínua expansão das taxas de êxodo rural, com consequências diretas sobre o meio urbano do país.

Segundo Graziano da Silva (1996b), pode-se dizer que o meio rural brasileiro também se urbanizou nas últimas décadas como resultado do processo de industrialização da agricultura, de um lado, e da penetração do mundo urbano-industrial naquilo que tradicionalmente era definido como rural, de outro. Como resultado desse duplo processo de transformação, a agricultura - que antes podia ser caracterizada como um setor produtivo relativamente autárquico e com o seu mercado de trabalho e equilíbrio interno - se integrou no restante da economia a ponto de náo mais poder ser separada dos setores que lhe fornecem insumos e/ou compram seus produtos.

Nesse cenário, verificou-se uma tendência de reduçáo do emprego estritamente agrícola no meio rural brasileiro no final do século XX, uma vez que, 
devido às características anteriormente mencionadas, a agricultura não absorve mais todo contingente populacional demandante de emprego. Com isso, é de se esperar a continuidade de deslocamentos das pessoas para o meio urbano e para as áreas metropolitanas, embora em quantidades inferiores àquelas verificadas até recentemente. Em geral, essas pessoas estão indo em busca de novas oportunidades de trabalho e de vida, o que implica a continuidade de pressóes adicionais sobre o mercado de trabalho urbano advindas dos impasses do trabalho rural (REZENDE et al., 1997).

Do ponto de vista econômico, dentre os aspectos mais visíveis destacam-se a ampliação da concentração da terra e da renda no meio rural. Especificamente no aspecto da terra, o país convive com uma das maiores taxas de concentração do mundo, fazendo com que o problema agrário permaneça como elemento central no cenário político nacional.

Do ponto de vista ambiental, ocorreu uma série de problemas, destacando-se a perda do solo pela erosão; a contaminação das águas nascentes e dos rios pelos agrotóxicos; a destruição em grau elevado das florestas naturais, sobretudo em funçáo da expansão desenfreada da fronteira agrícola, como é o caso recente da Amazônia, onde nos últimos 30 anos foram desmatados mais de 40 milhóes de hectares, sendo a maioria deles destinados para a criação pecuária, atividade altamente subsidiada pelo governo, porém com baixos retornos para a sociedade.

Com isso, conformou-se um processo dual de desenvolvimento rural no país que é marcado por premissas e perspectivas muito distintas. Por um lado, temos os espaços ocupados por grandes propriedades com monoculturas destinadas, em grande parte, aos mercados externos, transformando o país em um grande produtor e vendedor de produtos agroalimentares para os mercados mundiais. Nessa lógica, conforma-se um rural com pouca gente e com um sistema de produçáo cada vez mais especializado. Por outro, temos espaços rurais altamente diversificados produtivamente e com presença de diversos atores sociais rurais que conformam uma paisagem de um espaço com muita gente. Em grande medida, esse bloco está sendo dinamizado produtivamente pela agricultura familiar, setor este que representa a principal forma de inserção produtiva de milhares de trabalhadores rurais e que tem dado uma contribuição decisiva para o país, especialmente em termos de segurança alimentar e nutricional. 


\section{0 debate atual sobre a reforma agrária brasileira}

O debate atual sobre a reforma agrária no Brasil ganhou novos contornos após o grande boom das commodities no início do século XXI. Esse boom, em grande parte estimulado pelo aumento da demanda chinesa, provocou aumentos expressivos dos preços das principais commodities agropecuários, o que favoreceu a produção especializada e em larga escala, quase toda voltada ao setor externo da economia brasileira. É nesse contexto que o tema da reforma agrária está sendo rediscutido no meio acadêmico, revelando leituras bem distintas sobre o mundo agrário e suas perspectivas.

\section{I Teses favoráveis à Reforma Agrária ${ }^{3}$}

O tema da reforma agrária, dada sua natureza política, é marcado por distintas interpretaçôes, mesmo no campo que unifica os defensores dessa medida reformadora. Assim, percebe-se que existem diferentes concepçóes de um programa de reforma da estrutura agrária do país entre os próprios analistas situados no campo defensor da reforma. E o que os separa normalmente é a abrangência e o caráter da mesma. É exatamente sobre esse conjunto de proposições e argumentaçóes que esta subseção irá se debruçar, procurando identificar nas análises subsequentes as principais teses favoráveis à reforma agrária brasileira.

A constituição dos Complexos Agroindustriais (CAIs), a partir da década de 1970, representou "a integraçáo técnica intersetorial entre as indústrias que produzem para a agricultura, a agricultura propriamente dita e as agroindústrias processadoras, integração que só se torna possível a partir da internalização da produção de máquinas e insumos para a agricultura. Sua consolidação se dá pelo capital financeiro, basicamente através do SNCR e das políticas de agroindustrialização específicas instituídas a partir dos chamados fundos de financiamentos" (GRAZIANO DA SILVA, 1996c, p. 31).

Esse processo, segundo o autor, gerou uma nova dinâmica na agricultura brasileira, a qual recoloca problemas antigos, mas também novas questóes sobre os condicionantes estruturais desse padrão de desenvolvimento agrário.

3 Neste campo, destacamos alguns dos principais autores: Graziano da Silva (1981, 1996a, 1996b, 1999 e 2001); Delgado (2008); Carvalho filho (2007); Leite e Vieira de Ávila (2007). 
Dentre esses problemas, destacam-se os temas da propriedade da terra e das classes sociais rurais, além das profundas transformações nos planos da concentraçáo e centralizaçáo dos capitais aplicados no setor agropecuário.

Os impactos desse processo sobre a estrutura produtiva e sobre a relaçóes sociais rurais indicam, segundo o autor, um processo extremamente excludente, tanto em termos das regióes do país como dos segmentos de produtores, visto que apenas os médios e grandes proprietários de terras conseguiram se incorporar a essa nova etapa de mudanças no campo, enquanto que os agricultores familiares sofreram um forte processo de diferenciação.

Para o autor, essa diferenciação desenha uma polarização crescente que se explicita da seguinte forma:

[...] de um lado, uma perda gradativa do papel produtivo dos segmentos mais pobres de pequenos produtores, de modo a converter a terra que possuem em mero local de moradia ou, quando muito, em produção para autoconsumo da família; de outro, uma tecnificação crescente dos produtores familiares integrados aos complexos agroindustriais, aliando um patrimônio imobilizado cada vez maior a menores níveis de autonomia na organização de seu próprio processo produtivo. (GRAZIANO DA SILVA, 1996b, p. 173).

O primeiro grupo, segundo o autor, estará condenado a atividades marginais do ponto de vista produtivo, ou seja, "[...] estarão condenados à produção para autoconsumo ou, quando muito, para fornecimento direto às populaçôes locais com um nível tecnológico rudimentar" (GRAZIANO DA SILVA, 1996b, p. 176). Assim, ressalta-se que o nível de vida desses segmentos não integrados aos CAIs dependerá em muito das políticas públicas. É justamente nessa direção que apontam suas proposiçóes de política agrária.

Tomando como referência a questão sobre o que fazer com esses excluídos, ou seja, o que fazer com os "barrados do baile", os "descamisados", ou os "extremamente pobres" que, segundo o autor, na grande maioria são trabalhadores temporários sem vínculo empregatício e pequenos agricultores não modernizados que trabalham por conta própria. Desta forma, são propostas diversas políticas para esses segmentos, com destaque para o novo enfoque dado à política agrária.

Confrontado com a indagação se a reforma agrária é ainda necessária no Brasil, o autor vai responder afirmativamente e propor a tese de uma "reforma agrária não essencialmente agrícola”, ao mesmo tempo em que destaca os 
elementos básicos daquilo que ele considera como sendo um novo programa agrário para o país no início do século XXI. Inicialmente, observa-se que o autor defende uma reforma agrária de caráter mais "social" que "econômico" por entender que essa reforma teria a funçáo de gerar empregos, conter os fluxos migratórios e evitar a lumpenizaçáo do campo. Neste caso, o papel da reforma agrária seria o de auxiliar no equacionamento da questáo populacional do país, até que fosse completada a transição demográfica iniciada na última década. Para tanto, as políticas de um programa agrário dessa natureza teriam que ser menos produtivistas e mais voltadas ao não agrícola existente no espaço rural.

Por isso, a reforma agrária proposta

[...] não precisa ter mais um caráter estritamente agrícola, dado que os problemas fundamentais da produção e preços podem ser resolvidos pelos nossos complexos agroindustriais. É preciso hoje a reforma agrária para ajudar a equacionar a questão do nosso excedente populacional até que se complete a transição demográfica recém-iniciada. E a reforma agrária que permitisse a combinação de atividades agrícolas e não agrícolas teria a grande vantagem de necessitar de menos terra, o que poderia baratear significativamente o custo por família assentada, o que é forte limitante para a massividade requerida pelo processo distributivo, especialmente nos estados do sul e sudeste. (GRAZIANO DA SILVA 1999, p. 133).

Além dessa tese, o mesmo autor defende a tese de uma reforma agrária de abrangência regional, ao propor que "[...] a retomada da concepçáo de programa regionalizado de reforma agrária para o país, com a decretaçáo das zonas prioritárias previstas no antigo Estatuto da Terra, de modo a se conseguir a concentração de assentamentos agropecuários em determinadas regiōes" (GRAZIANO DA SILVA, 1999, p. 134).

Na verdade, Graziano da Silva (1999) defende a ideia de que é inviável uma intervenção massiva sobre a estrutura fundiária do país em função das restriçôes fixadas pela atual Constituiçâoo Federal que impedem uma ampla distribuição de terras em todo o país. Destaca-se como área prioritária para execução dessa proposta o sertão da região Nordeste do país.

Dessa forma, o autor acredita que

[...] a definição de regiões prioritárias permitiria estabelecer zonas reformadas com políticas públicas e regras diferenciadas do restante do país (como por exemplo, serviço de extensão 
rural específico, crédito do PROCERA etc.) que garantissem o sucesso dos novos produtores rurais nos seus primeiros anos, combinados com programas especiais de previdência social que garantissem renda mínima àquelas famílias rurais ou urbanas que não tivessem condições de serem beneficiadas com um lote. (GRAZIANO DA SILVA, 1999, p. 135).

Como medidas complementares a esse programa agrário, o autor propóe mais duas formas de intervenção governamental. Por um lado, devia ser alterada a concepção sobre o Imposto Territorial Rural (ITR), o qual precisaria ser "tratado como um tributo sobre a propriedade, à semelhança do IPTU, com participação decisiva das municipalidades na sua implantação" (idem, 136). Por outro lado, deveriam também ser apoiados programas de parcerias e arrendamentos como formas de acesso à terra pelos náo proprietários, especialmente nos locais onde o preço da terra é muito elevado. Neste caso, torna-se necessária a elaboração de uma legislação específica que regulamente a atividade visando a estimular essa prática no país.

Portanto, o autor afirma que

[...] a alternativa de gerar empregos no meio rural através da redistribuição do acesso à terra não se impõe apenas pelo lado microeconômico de representar menores custos [...] mas pelo fato de que uma política social compensatória do tipo 'passe no caixa' tem-se mostrada muito cara até mesmo para os países desenvolvidos; e a política de inserção em serviços pessoais urbanos requer um 'aprendizado' que não está ao alcance da maioria das famílias 'sem terra' e principalmente dos 'sem-sem' do nosso país; além, é claro, do custo macroeconômico da urbanização dessas famílias em termos de infraestrutura de transportes, habitação, saneamento básico etc. (GRAZIANO DA SILVA, 1999, p. 140).

Decorre dessa interpretação sua proposição - polêmica - de reabertura das discussóes sobre um programa de reforma agrária na regiáo Amazônica do país. E, com essas duas concepçóes de reforma agrária, o autor concluiu seus estudos afirmando que "[...] se não existissem outras razóes, bastaria essa: a pior das reformas agrárias que ao menos garante casa, comida e trabalho por uma geraçáo, custa menos da metade do que é gasto para manter alguém na cadeia" (GRAZIANO DA SILVA, 2001, p. 5).

Além das duas teses anteriores, destaca-se a tese de uma reforma agrária de caráter geral. Para Delgado, as condiçôes que fortaleceram a estratégia de expansão do agronegócio na agropecuária brasileira são, simultaneamente, a matriz da moderna questáo agrária, uma vez que essas mesmas condiçóes representam obstáculos reais ao desenvolvimento da agricultura familiar e dos 
assentamentos de reforma agrária (DELGADO, 2008). Assim, qualquer projeto de desenvolvimento que náo desbloqueie esses obstáculos no sentido de incorporar esses outros segmentos sociais rurais não será viável para a construção de um projeto de desenvolvimento autônomo do país.

De maneira clara e precisa, o autor aponta que essa incompatibilidade do projeto de desenvolvimento é peculiar, uma vez que este projeto se apoia em uma estratégia que mantém a estrutura agrária intocada, ao mesmo tempo em que fortalece apenas a expansão do agronegócio. Desta forma, a exclusão do campesinato brasileiro em detrimento da expansão do agronegócio não possibilita a construção de um crescimento sustentável do país e nem mudanças significativas na estrutura agrária.

Para Delgado, o início do século XXI está marcado por este novo "pacto" do setor agrário com apoio do Estado brasileiro, o que leva a uma brutal apropriação de capital no setor primário. Esse processo se revela na concentração da riqueza nacional, na expropriação dos recursos naturais e na geração de problemas nas contas externas (déficit externos), aspectos estes que recolocam a questão agrária como uma 'questão brasileira' e de caráter amplo.

Por isso, Delgado afirma que a reforma agrária segue sendo um tema pertinente e atual, uma vez que "[...] uma reforma agrária includente, de desenvolvimento e igualdade, não está fora da agenda, ao menos que se pense que não há desigualdade no país. O pessoal acha que desenvolvimento é modernização conservadora. É a moda Geisel, desenvolver o modelo do regime militar" (DELGADO, 2008, p. 1).

Nessas passagens, fica evidente o caráter da reforma agrária defendida pelo autor: uma reforma que promova a distribuição das terras e da renda e, ao mesmo tempo, que seja portadora da justiça e da equidade social. Essa posição se contrapóe ao projeto dominante, pois, segundo o autor,

[...] há uma orquestração nacional em defesa do modelo primário-exportador. Contra esta visão, tudo é colocado como atraso. Mas o atraso é justamente esse modelo, essa aliança do grande capital com os grandes latifúndios. O atraso é priorizá-lo em detrimento do crescimento industrial, do setor de serviços, da agricultura sustentável, da participação familiar. (DELGADO, 2008, p.4).

Há diversos pesquisadores (CARVALHO FILHO, 2007; LEITE; VIEIRA DE ÁVILA, 2007) que se associam a esta última tese por entender que 
diversos obstáculos estruturais do meio rural brasileiro continuam existindo devido a não efetivação de uma reforma agrária. Esses obstáculos, segundo esses autores, se situam nas esferas econômica, política e social e revelam que o desenvolvimento das forças produtivas está travado por normas, costumes, rotinas, relaçóes de poder e de trabalho, entre outras, fatos estes que decorrem de relaçóes historicamente estabelecidas entre os proprietários de terra e o restante da população rural. Tais relaçóes são fortemente marcadas pela condição desigual de acesso à terra, pela desigualdade de renda e pelo poder político dominante imposto pelo latifúndio.

$\mathrm{Na}$ verdade, trata-se de um grupo de pesquisadores que sustenta a ideia de que a não solução da questáo agrária continua sendo um impeditivo ao desenvolvimento mais equitativo e justo do país. A saída, neste caso, seria romper com o poder dos grandes latifúndios e das grandes empresas agropecuárias, via desconcentração da posse da terra. No entanto, isto não deve ser lido como se a reforma agrária se restringisse apenas a desconcentração fundiária, mas como um amplo programa público que tivesse em seu seio medidas que viessem a romper com o modelo produtivista e estabelecessem os parâmetros básicos de um modelo sustentável de desenvolvimento do país.

Finalmente, registra-se a tese que defende uma reforma agrária enquanto instrumento de combate ao latifúndio e de promoçáo de reformas gerais do país ${ }^{4}$. Esta tese é sustentada pelos principais movimentos sociais rurais, os quais entendem que a reforma agrária deve ter um caráter amplo e abranger todas as regióes do país como forma de inclusão de todos os segmentos populacionais. Isto daria ao processo reformador um caráter econômico, social, político e ecológico, uma vez que neste processo de mudança da estrutura fundiária estariam envolvidos segmentos sociais que historicamente tem atuado preservando os biomas brasileiros, fortemente ameaçados pela expansão do agronegócio exportador.

Partindo do pressuposto de que no Brasil nunca houve um verdadeiro programa de reforma agrária, razáo que faz do país o segundo em escala mundial em termos de concentração da propriedade da terra, defende-se o tema da reforma numa perspectiva mais ampla, ou seja, uma reforma enquanto política

4 Declaração final Encontro Nacional Unitário dos Trabalhadores Rurais e Povos do Campo, das Águas e das Florestas, realizado em Brasília no mês de agosto de 2012. 
de Estado que seja capaz de promover uma mudança radical na estrutura da propriedade da terra no país. Isto significa a adoção de políticas públicas que vão muito além de açóes pontuais sobre alguns latifúndios em determinados governos. Essa é a razão, segundo esses atores sociais, que explica por que entra governo, sai governo, mas a luta pela reforma agrária permanece na agenda política nacional.

Tendo clareza que está em curso uma grande ofensiva do capital sobre o processo produtivo rural, que, na prática, representa uma remontagem da modernização conservadora da agricultura que havia sido implementada durante o regime militar, porém interrompida durante o período de crises nas duas últimas décadas do século XX, analisa-se que tal retomada se dá via expansão primária da economia brasileira sob a liderança do agronegócio, considerado o inimigo comum para todos os atores desse campo político.

Para os defensores dessa tese, esse processo em curso representa, em essência, o revigoramento do modelo capitalista de produção agropecuária, cujas bases se assentam na expansão da produção e do lucro, mesmo que à custa da promoção de desigualdades e exclusão social, da dependência externa e da exploração predatória dos recursos naturais. O que importa, na verdade, é a acumulaçáo capitalista com base na superexploraçáo dos recursos naturais e da própria força de trabalho, levando a um processo de desterritorialização dos povos do campo, com graves consequências sociais e ambientais.

Em síntese, pode-se dizer que o conjunto dessas teses que defendem a pertinência da reforma agrária evidencia que o cenário atual é marcado pelo agravamento da contradiçáo entre os interesses exclusivos do capital em detrimento dos interesses de milhóes de trabalhadores rurais. Além da concentração da propriedade da terra, estão presentes também a exploração do trabalho, as migrações, as mortes, a perda da biodiversidade, a destruição dos solos e das águas, a desnacionalização das terras, a insegurança alimentar, a ampliação dos conflitos agrários, a exclusão social, etc., temas estes que configuram a face perversa do atual modelo de desenvolvimento rural, que se expandiu sem que tenha sido feito a reforma agrária. É exatamente esse cenário que os defensores dessas teses pretendem alterar, buscando não somente promover mudanças nas áreas rurais, mas alterar o próprio rumo do desenvolvimento do país. 


\subsection{Teses contrárias à Reforma Agrária ${ }^{5}$}

Todo autor que estuda por um longo período um determinado tema como é o caso da reforma agrária brasileira - precisa ser interpretado levando-se em consideração o acúmulo de suas análises em um determinado período histórico. Isso pressupóe ao interprete observar cuidadosamente a trajetória desse autor no sentido de captar suas possíveis releituras de processos sociais que poderão influenciar e/ou alterar a linha analítica que vinha sendo seguida.

É exatamente isso que será feito nesta seção ao se procurar sistematizar as teses e proposiçóes sobre a reforma agrária de alguns dos mais renomados cientistas sociais brasileiros que, ao longo das últimas décadas, deram grandes contribuiçôes ao debate, porém encontrando-se no momento atual em um campo oposto aos defensores da reforma agrária. Registre-se, desde logo, que não se trata aqui de fazer qualquer juízo de valor sobre essas novas proposiçóes desses autores, ao contrário, o que se pretende é sistematizar e esclarecer os principais argumentos acadêmicos que sustentam essas proposiçóes que caminham em sentido oposto àquelas dos autores discutidos no subitem anterior.

Assim, destacamos a primeira tese contrária à reforma agrária enunciada da seguinte forma: o tempo da reforma agrária acabou. Essa frase de impacto sintetiza a argumentação do autor sobre o tema, uma vez que

[...] se fosse apenas por uma decisão exclusivamente presidencial, nem mesmo teríamos mais ações em reforma agrária. Lula não interrompe tal programa em face das inevitáveis consequências políticas e do poder de inércia que tem tal bandeira na visão de alguns setores sociais, incapazes de perceber que o mundo rural brasileiro mudou radicalmente nos últimos 30 anos. Este relativo distanciamento da parte principal do governo em relação à reforma agrária reflete o que todos sabemos, mas ninguém parece ter coragem de dizer claramente: o tempo histórico da reforma agrária passou. (NAVARRO, 2007, p. 3).

Apesar de a argumentação ser posta dessa forma, registre-se que ela está amparada em outras teses do referido autor sobre as mudanças das últimas décadas que ocorreram no campo, as quais ganharam maior dimensão no cenário social e político brasileiro nas duas últimas décadas. Assim, em artigo escrito no ano de 2002, o autor afirma que os anos recentes introduziram

5 Registre-se que atualmente Zander Navarro é, sem dúvida, o principal autor que se posiciona contra a reforma agrária. Por isso, seus estudos servirão de base analítica neste subitem. 
transformaçóes importantes no mundo rural que representaram "por um lado, um golpe mortal na dominação social e econômica da grande propriedade territorial, em amplas regióes rurais. Por outro lado, contudo, as mesmas modificações podem ter produzido a liquidação definitiva da reforma agrária como uma reivindicaçáo nacional e decisiva para os destinos históricos do país" (NAVARRO, 2002, p. 2).

Na sequência, esse mesmo autor apresenta um conjunto de fatores que, em sua interpretação, corroeram a proeminência política e econômica da grande propriedade rural. Neste caso, destacam-se o encurralamento econômico e financeiro da atividade agrícola, em especial da agricultura empresarial; a perda de importância da chamada bancada ruralista; a redução do peso político da agricultura empresarial e da grande propriedade territorial nas grandes decisóes nacionais; a urbanização acelerada das últimas décadas e seus impactos na vida rural que também se urbaniza; o sistema de produção agropecuária e de comercializaçáo garantiu o abastecimento alimentar, dentre outros citados.

Nessa lógica interpretativa, aparece uma segunda tese contrária à reforma agrária enunciada da seguinte forma: o problema agrário foi rebaixado e os pressupostos da reforma agrária deixaram de existir. Neste caso, mostra-se que as transformaçóes operadas nas áreas rurais no período recente impuseram

[...] uma dramática inflexão na questão agrária no Brasil, virtualmente sepultando-a em sua versão clássica... já que as áreas rurais experimentaram, especialmente a partir da segunda metade dos anos noventa, uma silenciosa e profunda revolução econômico-produtiva que rapidamente enraizou uma sociabilidade distinta do passado agrário e suas representações ainda que estas se mantenham em boa parte do imaginário coletivo nacional. (NAVARRO, 201 I, p. 98-99).

Com isso, afirma-se que os últimos 15 anos apresentaram a "[...] formação de uma geraçáo de agricultores com aguçada sensibilidade capitalista motivados pela elevaçáo dos preços das mercadorias agrícolas no mesmo período, crescimento estimulado pela demanda internacional, particularmente a chinesa" (NAVARRO, 2011, p. 99). Percebendo que este não é um movimento homogêneo e que a agricultura beneficiada foi a de maior escala, o autor faz a ressalva de que os produtores de menor porte náo ficaram totalmente à margem desse processo de expansão capitalista. Para tanto, destaca o papel crucial do PRONAF, as políticas sociais e, mais recentemente, a política de transferência de renda. Ou seja, a pobreza rural não foi totalmente esquecida! 
Esse processo de mudanças levou a um crescimento expressivo da produtividade dos fatores, tanto na agricultura como na pecuária, em função de "uma notável aceleraçáo de incorporação tecnológica a partir de meados da década de 1990" (NAVARRO, 2011, p. 99). Assim, essa nova realidade rural

[...] mostra que praticamente não existe mais uma questão agrária no Brasil, mesmo que os padrões de desigualdade social permaneçam praticamente intocados, ilustrados pela distribuição da propriedade fundiária [...] isto porque quando considerado apenas o fator terra, esta não é mais contradição que tem a mesma dimensão do passado e gradualmente nos acostumamos com este padrão fundiário. (NAVARRO, 2011, p. 101-102).

As razões explicativas para esse comportamento, segundo o autor, decorrem da combinação das mudanças antes mencionados com algumas tendências em andamento. Nesse caso, destacam-se a já mencionada urbanização do país, fator que traz consigo o corolário da inexistência de demanda social para mudar a estrutura fundiária atual que deverá se manter concentrada; a expansão da demanda internacional para a agricultura comercial brasileira, fato que a tornará mais robusta e espraiará uma sociabilidade capitalista; a manutenção de um padrão agrário bimodal com ampla dominaçáo da agricultura comercial nas diversas regióes do país, uma vez que apenas nos três estados sulinos haverá espaço para agricultura de menor porte; as potencialidades produtivas da agropecuária do país e o potencial derivado da bioenergia aprofundarão ainda mais a acumulaçáo de capital gerada pela agricultura.

Para o autor, o resultado combinado desse processo em curso fez com que a questáo agrária brasileira praticamente deixasse de existir, já que apenas

[...] alguma dimensão de conflito social deverá permanecer, mas vai se tornando residual com o passar do tempo, reduzindo-se à esfera trabalhista, nas poucas regiões onde permanece importante um contingente de trabalhadores rurais assalariados... enquanto as outras dimensões de conflito (no interior das cadeias produtivas e entre Governo Federal e interesses setoriais) continuarão ocorrendo. Passivos históricos, como a apropriação fraudulenta da terra em diversas regiões e em épocas distintas, a esta altura não têm a menor possibilidade política de serem revistos, tendendo a ser definitivamente legalizados. (NAVARRO, 2011, p. 105-106).

A consequência principal desse processo, segundo o autor, é que a questáo social deixou o campo e foi para as cidades e, com isso, a reforma agrária tradicional começou a entrar nos livros de história "como uma faceta do 
passado" (NAVARRO, 2011, p. 105-106). Isso porque as mudanças ocorridas no campo brasileiro, anteriormente mencionadas, alteraram totalmente a natureza da questáo agrária. Se esta ainda existir, ela precisaria lidar, segundo o autor, com apenas três temas: o poder econômico dos grandes grupos agroindustriais, que, sem regulação estatal, formarão setores oligopolizados; a face trabalhista, que é restrita apenas ao tema dos direitos historicamente negados pelos proprietários de terra e visa ao estabelecimento de relaçóes de trabalho "consentâneas com a modernidade capitalista"; e a face ambiental, que será a mais problemática nos anos vindouros devido às ameaças decorrentes das mudanças climáticas.

Para demonstrar a não necessidade de uma política pública de reforma agrária que, no passado simbolizava a própria questáo agrária, o autor destaca dois aspectos centrais. Por um lado,

[...] processos de reforma agrária ocorreram, em sua maioria, entre os anos cinquenta e setenta do século passado. Posteriormente saíram de moda, sendo o Brasil o único país que insiste com tal política [...] e, por outro, porque a reforma agrária significa transferir direitos de propriedade de forma irrecorrivel, sendo por isto mesmo que apenas o Estado pode implementá-la e operá-la. Desta forma, com as ondas democratizantes do período contemporâneo, tais atos de força foram se tornando crescentemente implausíveis do ponto de vista do jogo político democrático. (NAVARRO, 201 I, p. 107-108).

Uma terceira tese contrária à reforma agrária diz que a influência da terra é pequena em relação ao valor da produção. Essa tese se origina a partir das formulaçóes de um grupo de pesquisadores e acadêmicos liderados, em sua maioria, por engenheiros agrônomos com formaçáo parcial em economia e também por economistas, ambos formados sob o domínio do pensamento econômico neoclássico, os quais passaram a interpretar a realidade agrária brasileira exclusivamente a partir da ótica da produtividade dos fatores de produção, em especial da tecnologia, conformando aquilo que muitos estudiosos denominam de "o grupo dos produtivistas".

Recentemente esse grupo divulgou alguns estudos em que as abordagens convencionais referidas aparecem com maior clareza. Tomando como referência o Censo Agropecuário do IBGE de 2006, separaram-se do universo total de estabelecimentos agropecuários do país aqueles estabelecimentos com 
renda bruta ${ }^{6}$ acima de dez salários mínimos daqueles com renda entre dois a dez salários de referência e daqueles com renda bruta inferior a dois salários. Neste último caso, chegou-se à conclusão que existem 3.775.826 estabelecimentos nessa condição no universo total de 5.175.489 estabelecimentos existentes no país no último censo. Além disso, pelo critério da renda bruta, chegou-se à conclusão que o primeiro grupo de estabelecimentos responde por aproximadamente $85 \%$ do valor da produção total, enquanto que o grupo dos mais de 3 milhóes de estabelecimentos respondem por menos de $5 \%$ da produção total (ALVES; ROCHA, 2010) ${ }^{7}$.

Feita essa constatação a partir dos dados censitários, partiu-se para a elaboração de um diagnóstico da realidade rural brasileira. Assim, concluiu-se que há claramente dois grupos de agricultores: os bem-sucedidos e os malsucedidos, porque a expressão produtiva dos primeiros se deve à modernização da agricultura. Para Alves, Souza e Rocha (2012, p. 45),

[...] como a pequena produção gastou muito menos por hectare, ela deve estar sofrendo discriminação pelo mercado ou discriminação que depende da personalidade do agricultor [...] fazendo com que os produtores malsucedidos apresentem produtividade por hectare e total dos fatores muito menores que os bem-sucedidos. Decorre daí que os malsucedidos não sabem administrar a tecnologia.

Os autores também encontraram justificativas para o problema, uma vez que

[...] o insucesso deve-se a escolhas errôneas de tecnologias e a má administração do estabelecimento e da tecnologia. Deve-se também a restrições intrínsecas ao próprio produtor (muito conservador quanto ao risco) e as restrições externas, principalmente do crédito, que impedem a exploração adequada dos recursos do estabelecimento. (ALVES; SOUZA; ROCHA, 2012, p. 47).

Ou seja, a culpa é dessa massa de pequenos produtores que são conservadores e não souberam se modernizar. Ora, quem acompanhou atentamente o que ocorreu durante o processo de modernizaçáo da agricultura brasileira sabe perfeitamente distinguir a superficialidade desse diagnóstico diante da

6 Os autores justificam o uso da renda bruta pelo fato de ter "a vantagem de escapar do problema relativo às imputações em terra, benfeitorias etc." (ALVES; ROCHA, 2010, p. 277).

7 Para os autores, o potencial migratório rural-urbano encontra-se justamente neste grupo majoritário. 
realidade vivenciada por milhóes de famílias de trabalhadores rurais que foram excluídas do processo produtivo exatamente pelo caráter e natureza do processo modernizante ${ }^{8}$.

Chama atenção que esse grupo de pesquisadores sequer menciona nessas análises a problemática agrária, a não ser pontualmente quando se afirma que "[...] a influência da terra é pequena em relaçáo à da tecnologia no que diz respeito ao valor da produção" (ALVES; SOUZA; ROCHA, 2012, p. 46). Isso porque "[...] a área do estabelecimento tem pequeno poder para explicar a concentração. Nesta explicação, a maior responsabilidade é da tecnologia" (ALVES; SOUZA; ROCHA, 2012, p. 61).

Diante do cenário diagnosticado, foram propostas duas estratégias distintas. Assim, a saída para o grupo de agricultores com renda bruta entre $02 \mathrm{e}$ 10 salários mínimos (ao redor de 1 milhão de estabelecimentos) "[...] é fazer cada hectare produzir mais, ou seja, usar tecnologias que poupem a terra [...]. Portanto, a mecanizaçáo, mesmo que de pequeno porte, tem que vir ao lado da tecnologia bioquímica. Isso exige assistência técnica de boa qualidade, aliado ao crédito rural" (ALVES; ROCHA, 2010, p. 284). Ou seja, trata-se de modernizar também essa pequena parcela à luz da trajetória daquele segmento minoritário que apresenta renda bruta elevada.

Já para o grupo malsucedido (3.775.826 estabelecimentos agropecuários), a solução para as baixas condiçóes de renda não virá, segundo os autores, nem pela agricultura e muito menos por políticas de reforma agrária. Para esse grupo, "[...] forte dose de política social, de caráter assistencialista, se faz necessária para manter as famílias a ele vinculadas nos campos" (ALVES; ROCHA, 2010, p. 288). Assim, os autores defendem que este enorme grupo de produtores rurais deveria ser atendido pelo Ministério do Desenvolvimento Social e Combate à Fome e náo pela estrutura institucional agrária do país (MAPA e MDA).

\section{Considerações finais}

Desde os primórdios da formação social brasileira, a questão da terra aparece como elemento central que explicita as próprias contradiçóes dessa

8 Este capitulo da história agricola e agrária brasileira está fortemente documentado na literatura especializada. 
formação societária. Assim, durante o processo de ocupação imperial do país, a terra funcionou como importante instrumento para atender aos interesses dos negócios internacionais, seja produzindo bens demandados pelo comércio mundial da época, seja estabelecendo uma estrutura produtiva monocultora assentada no poder político dos "senhores dos engenhos".

Com a emancipação do país e a consequente formação da república federativa, esse problema se agravou, uma vez que a terra, enquanto um bem natural, passou a ser uma mercadoria privada, cujo acesso permaneceu restrito apenas às camadas da população capazes de adquiri-la. Com isso, foram sendo estabelecidas as condiçóes para que o Brasil se tornasse um dos países do mundo com os maiores índices de concentraçáo privada da posse da terra. Esse fato foi documentado pelo último Censo Agropecuário (IBGE, 2006), quando se constatou que a desigualdade na distribuiçáo da terra revela, a um só tempo, processos pretéritos e contemporâneos do modo como os recursos naturais são apropriados no Brasil.

Essa é a razão que faz com que a questão da propriedade da terra permaneça presente na agenda e no debate político nacional até os dias atuais, fato que perpassou pelos diversos ciclos econômicos (açúcar, mineraçáo, algodão, pecuária e café) e se manteve presente no cenário econômico, social e político do país. Mesmo assim, nota-se que uma parte expressiva da literatura especializada sobre o meio rural brasileiro relegou a questáo agrária a um plano secundário, defendendo que a própria reforma agrária se transformou em uma proposta historicamente superada. Em grande medida, argumenta-se que o capitalismo agrário brasileiro resolveu, sem precisar fazer alteraçóes estruturais, aqueles problemas que a reforma agrária se propunha a resolver no passado recente.

É neste cenário de mudanças que o debate clássico sobre a reforma agrária brasileira ganhou novos contornos nos tempos atuais. Se, nas primeiras décadas do pós-guerra, a não solução da questão agrária era vista unanimemente entre os analistas agrários como um impeditivo ao desenvolvimento do país, nos tempos presentes, muitos analistas de tradição agrarista passaram a tratá-la como sendo um impeditivo à continuidade do próprio desenvolvimento rural, dado o nível obtido após a política de modernização conservadora.

Essa política alterou totalmente a dinâmica da agricultura brasileira nas últimas décadas e, segundo esses intérpretes, removeu todos os resquícios que 
poderiam se transformar em impeditivos ao desenvolvimento. Para tanto, argumenta-se que o capitalismo agrário do século XXI precisa apenas intensificar o uso de tecnologias, uma vez que o aumento absoluto da produçáo virá dessas e não da incorporação de mais áreas de terras ao processo produtivo agrícola, via política agrária. Evidentemente que essas premissas analíticas pressupóem a inexistência de uma questáo agrária a se resolver no país, significando que a bandeira da reforma agrária se transformou em uma luta obsoleta e sendo apenas "parte da história e do passado".

Ao longo do texto, foi possível perceber as modificaçóes sofridas pela trajetória histórica que marcou o debate sobre o papel da reforma agrária na sociedade brasileira. Se, nas décadas iniciais do período do pós-guerra, ela era considerada como um dos instrumentos mais decisivos na definição dos rumos do desenvolvimento do país, hoje se verifica que, diante das transformaçóes estruturais ocorridas na esfera rural, há distintas concepçóes sobre o papel da reforma agrária no debate sobre o modelo de desenvolvimento que se quer construir para o país.

Assim, por mais que se possa tergiversar sobre alguns aspectos, a questáo central que se coloca no momento é o que fazer com o universo de 3.775 .826 estabelecimentos agropecuários que são explorados por agricultores familiares, a grande maioria deles com pouca terra e que se encontram fragilizados socialmente. Essa não é uma questáo menor, uma vez que esses estabelecimentos respondem por $73 \%$ do total de estabelecimentos do país.

É com este cenário de fundo que se move o debate acadêmico apresentado nas seçóes anteriores, pois, além de ele ser bem menos incipiente que nos períodos anteriores, observa-se também que está muito mais afeito à ideologia dominante emanada pela concepçáo do agronegócio do que pela realidade efetiva do mundo rural. Neste sentido, náo é de se estranhar a existência de teses que passaram a defender a inviabilidade da reforma agrária enquanto um mecanismo eficaz para promover, além da produção agropecuária, o combate à pobreza e a desigualdade social que impera neste espaço geográfico.

Essas teses, na verdade, procuram estabelecer um novo perfil sobre o papel da reforma agrária no desenvolvimento brasileiro, uma vez que a realidade atual não a justificaria sequer como instrumento para solucionar os problemas sociais rurais, tendo em vista que a "modernização conservadora" já resolveu o problema do capitalismo agrário brasileiro, problema este que tanto preocu- 
pava os analistas clássicos que a interpretaram como um dos pilares do modelo de desenvolvimento do país.

É nessa direção que devem ser analisadas as teses conservadoras que buscam isolar o problema agrário da dinâmica rural, ou seja, tenta-se buscar a soluçáo para esse enorme contingente de pessoas fora da realidade agrária, como se destinar a essas pessoas parcos recursos de programas assistenciais fosse capaz de resolver um problema histórico de pobreza e de exclusão social, cuja matriz está diretamente relacionada às condiçôes de acesso a dois bens essenciais: terra e água. Não é por menos que o problema se revela de forma mais expressiva exatamente nas regióes onde o acesso a esses dois bens naturais foi historicamente negado.

De outro lado, como vimos, encontra-se um grupo expressivo de pesquisadores e estudiosos da questáo agrária brasileira que entende que a reforma agrária ainda tem um papel importante a desempenhar nos rumos do desenvolvimento do país, especialmente em termos de auxiliar a equacionar o problema demográfico, bem como atuar tanto na esfera produtiva como na melhoria das condiçóes sociais e econômicas das populaçóes rurais fragilizadas. O texto mostrou ser esta concepção (defesa da reforma agrária) o elo aglutinador entre esses diferentes grupos, não escondendo a existência de divergências entre esses intérpretes quanto ao caráter e abrangência da reforma agrária.

Em grande medida, o que sustenta a argumentação dos defensores dessa posição são dois fatores fundamentais: por um lado, a existência de enorme quantidade de terra improdutiva no país e, por outro, a existência de mais de três milhóes de famílias de sem terras e/ou de trabalhadores rurais com pouca terra, as quais sobrevivem em regióes que apresentam elevados índices de desigualdades econômicas e sociais. Por isso, entendem que náo se pode prescindir do uso de um instrumento eficaz - como é o caso da reforma agrária - para tentar reverter esse cenário, política que foi implementada por grande parte dos países que hoje são considerados desenvolvidos.

\section{Referências}

ALVES, E; SOUZA, G. da S.; ROCHA, D. de P. Lucratividade da agricultura. Revista de Política Agrícola, ano XXI, n. 2, p. 45-65, abr./maio/jun. 2012. 
ALVES. E.; ROCHA, D. P. Ganhar tempo é possível? In: GASQUES, J. G.; VIEIRA FILHO, J. E.; NAVARRO, Z. (Org.). A agricultura brasileira: desempenho, desafios e perspectivas. Brasília: IPEA. 2010. p. 275-290.

CARVALHO FILHO, J. J. O esvaziamento da reforma agrária sob Lula. Folha de São Paulo, p. A3, 1 fev. 2007.

DELGADO, G. Concentração, política agrária e violência no campo: dez anos. In: SYDOW, E. S.; MENDONÇA, M. L. Direitos Humanos no Brasil 2009 - Relatório da Rede Social de Justiça e Direitos Humanos. Brasília: Rede Social de Justiça e Direitos Humanos, 15 out. 2009. p. 39-46. Disponível em: <http://www.social.org.br/dh\%20no\%20brasil\%202009. pdf>. Acesso em: 21 dez. 2015.

Cantar um réquiem. In: MERLINO, T.; MENDONÇA, M. L. Direitos Humanos no Brasil 2012 - Relatório da Rede Social de Justiça e Direitos Humanos. Brasília: Rede Social de Justiça e Direitos Humanos, 2012. p. 23-30.

A questáo agrária no Brasil, 1950-2003. In: JACCOUD, L.; SILVA, F. B. da; DELGADO, G. C.; CASTRO. J. A. de; CARDOSO JR., J. C.; MÁRIO THEODORO, M.; BEGHIN, N. Questão Social e Políticas Sociais no Brasil Contemporâneo. Brasília: IPEA, 2005. p. 51-90.

Questão agrária hoje. Revista da ABRA, ano 35, v. 1, n. 2, p. 27-40, 2014.

PEREIRA FILHO, J. Lula abandonou a reforma agrária. Jornal Brasil de fato, p. 5, 18 abr. 2008. Disponível em: <http://cptne2.org.br/index.php/publicacoes/noticias/noticias/1924lula-abandonou-a-reforma-agraria-diz-pesquisador>. Acesso em: 21 dez. 2015.

GASQUES, J.G.; VILLA VERDE, C.M. Crescimento da agricultura brasileira e política agrícola nos anos oitenta. Agricultura em Sáo Paulo. ano 37, n.1, p.183-204, 1990.

GRAZIANO DA SILVA, J. Progresso técnico e relaçóes de trabalho na agricultura. São Paulo: Hucitec, 1981.

O que é a questão agrária. São Paulo: Brasiliense, 1985a.

. Para entender o Plano Nacional de Reforma Agrária. São Paulo: Brasiliense, 1985b.

A nova dinâmica da agricultura brasileira. Campinas: UNICAMP-IE, 1996a.

Por uma reforma agrária não essencialmente agrícola. Revista Agroanalysis, ano 16, v. 3, p. 8-11, mar. 1996 b. 
O novo rural brasileiro. Campinas: UNICAMP-IE, 1999. (Coleção Pesquisa, n. 1). Ainda precisamos de reforma agrária no Brasil? Revista Ciência Hoje, v. 27, n. 170, p. 81-83, abr. 2001.

A reforma agrária no século XXI. Jornal Folha de São Paulo, 20 abr. 2007a. . Uma nova agenda para a reforma agrária. Jornal Valor Econômico, 27 jun. 2007b. Ainda precisamos de reforma agrária no Brasil? Revista Ciência Hoje, v. 27, n. 170, p. 81-83, abr. 2011.

INSTITUTO BRASILEIRO DE GEOGRAFIA E ESTATÍSTICA - IBGE. Censo Agropecuário de 2006.

LEITE, S. P. (2008). A reforma agrária hoje ainda é necessária. Entrevista ao Jornal IHu On-line Unisinos, 2008, p.9-11.

LEITE, S. P.; VIEIRA DE ÁVILA, R. Reforma agrária e desenvolvimento na América Latina: rompendo com o reducionismo das abordagens economicistas. Revista de economia e Sociologia Rural, v. 45, n. 3, p. 777-805, jul./set. 2007.

NAVARRO, Z. MST: decifrar é preciso. Porto Alegre: Programa de Pós-Graduação em Desenvolvimento Rural da UFRGS, 1 de maio 2000. p. 1-8.

. O Brasil precisa da reforma agrária? Jornal Muito Mais, São Paulo, p. 5, 15 de jan. 2002.

Jornal Folha de Sáo Paulo (entrevista especial), São Paulo, p. A3, 22 fev. 2007.

Até quando a desrazão agrária? Jornal Folha de Sáo Paulo, São Paulo, p. A-3, 30 mar. 2009.

Meio século de transformaçôes do mundo rural brasileiro e a ação governamental. Revista de Política Agrícola, Ano XIX, p. 107-118, jul. 2010.

. A vida e os tempos da questão agrária no Brasil. In: TEIXEIRA, E. C. et al. (Org.). As questóes agrárias e de infraestrutura de transportes para o agronegócio. Viçosa: Editora da UFV, 2011. p. 85-112.

- Tierra, democracia y capitalismo: La imporbable convergência (El caso latinoamericano, com énfasis em Brasil). Revista Espanola de Estudios Agrosociales y Pesqueros, n. 231, p. 93-136, 2012. 
REZENDE, G. C. et al.. Abertura comercial, financiamento das importaçóes e o impacto sobre o setor agrícola. IPEA (Texto para Discussão n. 498), 1997.

VALENTE, A. L. E. F. Mas qual a reforma agrária? Revisitando um debate inconcluso. Revista Estudos Sociedade e Agricultura, v. 17, n. 1, p. 86-120, 2009.

Recebido em: 07/04/2016.

Aceito em: 23/09/2016.

\section{The Land Reform Debate in Brazil Under the Current Rural Context}

\section{Abstract}

In this article we summarize a discussion about the main thesis about the pertinent of land reform in the beginning of twenty first century in Brazil. The papers starts with general contextualization of the Brazilian rural situation after a decades of structural reforms followings the discussion of thesis against and favorable the land reform. On the one side we observe that exist an expressive number of researchers that are defending the land reform because they are understanding that this policy is very important to combat the poverty and social inequalities, and the other side we saw also another group of researchers that are against the land reform because they believe that the time for the land reform is already gone. We concluded that academic debate about agrarian reform now is less important than it was in the post war period, especially in the 1960s.

Keywords: Brazil. Rural development. Agrarian reform. 